\title{
Pharmacokinetics and pharmacodynamics of propranolol in hypertensive patients after sublingual administration: systemic availability
}

\section{A.P. Mansur, S.D. Avakian, R.S. Paula, H. Donzella, \\ S.R.C.J. Santos and J.A.F. Ramires}

Departamento de Clínica Médica, Instituto do Coração, Universidade de São Paulo, SP, Brasil
Correspondence

\section{A.P. Mansur}

Departamento de Clínica Médica Instituto do Coração, USP

Av. Dr. Enéas C. de Aguiar, 44 05403-000 São Paulo, SP

Brasil

Fax: 55 (011) 3068-5348

E-mail: apmansur@usp.br

Publication supported by FAPESP.

Received September 26, 1997 Accepted February 17, 1998

\section{Abstract}

The bioavailability of propranolol depends on the degree of liver metabolism. Orally but not intravenously administered propranolol is heavily metabolized. In the present study we assessed the pharmacokinetics and pharmacodynamics of sublingual propranolol. Fourteen severely hypertensive patients (diastolic blood pressure (DBP) $\geq 115$ $\mathrm{mmHg}$ ), aged 40 to 66 years, were randomly chosen to receive a single dose of $40 \mathrm{mg}$ propranolol hydrochloride by sublingual or peroral administration. Systolic (SBP) and diastolic (DBP) blood pressures, heart rate (HR) for pharmacodynamics and blood samples for noncompartmental pharmacokinetics were obtained at baseline and at $10,20,30,60$ and $120 \mathrm{~min}$ after the single dose. Significant reductions in BP and HR were obtained, but differences in these parameters were not observed when sublingual and peroral administrations were compared as follows: SBP (17 vs $18 \%, \mathrm{P}=\mathrm{NS})$, DBP (14 vs $8 \%, \mathrm{P}=\mathrm{NS}$ ) and HR ( 22 vs $28 \%, \mathrm{P}=\mathrm{NS})$, respectively. The pharmacokinetic parameters obtained after sublingual or peroral drug administration were: peak plasma concentration $\left(\mathrm{C}_{\mathrm{MAX}}\right): 147 \pm 72 \mathrm{vs} 41 \pm 12 \mathrm{ng} / \mathrm{ml}$, $\mathrm{P}<0.05$; time to reach $\mathrm{C}_{\mathrm{MAX}}\left(\mathrm{T}_{\mathrm{MAX}}\right): 34 \pm 18$ vs $52 \pm 11 \mathrm{~min}, \mathrm{P}<0.05$; biological half-life $\left(\mathrm{t} 1 / 2_{\mathrm{b}}\right): 0.91 \pm 0.54$ vs $2.41 \pm 1.16 \mathrm{~h}, \mathrm{P}<0.05$; area under the curve $\left(\mathrm{AUC}_{\mathrm{T}}\right): 245 \pm 134 \mathrm{vs} 79 \pm 54 \mathrm{ng} \mathrm{h}^{-1} \mathrm{ml}^{-1}, \mathrm{P}<0.05$; total body clearance $\left(\mathrm{CL}_{\mathrm{T}} / \mathrm{F}\right): 44 \pm 23$ vs $26 \pm 12 \mathrm{ml} \mathrm{min}^{-1} \mathrm{~kg}^{-1}, \mathrm{P}=\mathrm{NS}$. Systemic availability measured by the $\mathrm{AUC}_{\mathrm{T}}$ ratio indicates that extension of bioavailability was increased 3 times by the sublingual route. Mouth paresthesia was the main adverse effect observed after sublingual administration. Sublingual propranolol administration showed a better pharmacokinetic profile and this route of administration may be an alternative for intravenous or oral administration.
Key words

- Propranolol

- Pharmacokinetics

- Pharmacodynamics

- Arterial hypertension

- Sublingual vs peroral administration 


\section{Introduction}

For many years, beta-adrenergic antagonists were prescribed to patients with essential arterial hypertension, ischemic heart disease, cardiac arrhythmias and other cardiovascular diseases. These drugs have proved to be effective and safe $(1,2)$. Propranolol, a prototype of this class of drugs based on competitive inhibition of catecholamine binding at beta-adrenoceptor sites, is conventionally prescribed by the peroral route, but intravenous administration is also available and usually prescribed for patients with acute syndromes (3). Propranolol is a lipid-soluble compound and its dosage form as tablet is completely absorbed by the peroral route. Due to its extensive first-pass hepatic effect by the peroral route, the drug shows a short plasma half-life (4). However, the high interindividual variation of plasma propranolol concentration after peroral administration, approximately 20 -fold, depends largely on hepatic metabolism and total body clearance (5). A dose-dependent bioavailability was reported for plasma propranolol levels higher than $20 \mathrm{ng} / \mathrm{ml}$, the therapeutic drug concentration for patients with essential hypertension (2). The rectal (6) and intranasal (7) routes have been used to avoid a first-pass hepatic effect.

We have previously reported the efficacy of sublingual propranolol administration in

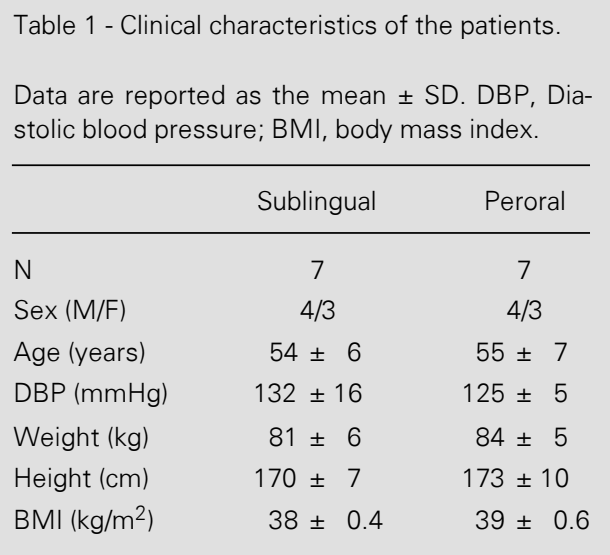

reducing blood pressure (BP) and heart rate (HR) in patients with severe arterial hypertension (8), although we did not measure plasma propranolol concentrations. The present study was conducted to investigate the pharmacokinetics and pharmacodynamics of this unusual route of propranolol administration in patients with severe essential arterial hypertension.

\section{Material and Methods}

Patients

Fourteen outpatients with essential arterial hypertension, aged 40 to 66 (mean 55.4 \pm 8.6 ) years, 8 males and 6 females, were investigated (Table 1). To be included, patients should have diastolic blood pressure (DBP) over $115 \mathrm{mmHg}$ without any antihypertensive medication for at least two weeks before the study. Patients with congestive heart failure, second- or third-degree atrioventricular block, bradycardia ( $<60 \mathrm{bpm})$, bundle branch block, sick sinus syndrome, pulmonary, liver, renal, metabolic, inflammatory, or neoplastic diseases or previous hypersensitivity to any beta-blocker were excluded.

Study design

Patients were submitted to a general clinical and physical examination before the investigation to exclude any important disease other than arterial hypertension. Patients selected were randomized to receive the conventional form of propranolol hydrochloride (40 mg/tablet) by the sublingual or peroral route. BP, HR and blood samples for propranolol assay were obtained at baseline and after drug administration. Three measurements were made one minute apart after 10 min of rest in a quiet place using a standard mercury sphygmomanometer for BP and the Korotkoff phase V for DBP, followed by a one-minute heart rate count, and the mean 
values were calculated. Adverse effects were monitored simultaneously.

Blood collection and propranolol assay

Whole blood was collected into heparinized plastic vials prior to and at 10,20,30, 60 , and $120 \mathrm{~min}$ after a single propranolol dose. After centrifugation at 2,000 g for 15 min, plasma was transferred to plastic tubes and stored in a freezer at $-20^{\circ} \mathrm{C}$ until the time for assay. Plasma propranolol concentration was determined after double extraction followed by fluorimetry, based on a previously reported method (9). Briefly, $1 \mathrm{ml}$ plasma was transferred to a glass tube $(15 \times 150$ $\mathrm{mm}), 1 \mathrm{ml} 10 \% \mathrm{~K}_{2} \mathrm{CO}_{3}$, $\mathrm{pH} 10.1$, was added and the drug was extracted with $6 \mathrm{ml}$ toluene for $5 \mathrm{~min}$ in a vortex mixer. After centrifugation at 3,000 $\mathrm{g}$ for $15 \mathrm{~min}$, the supernatant was transferred to a clean glass tube and $5 \mathrm{ml}$ of the organic phase was supplemented with $1.5 \mathrm{ml} 5 \mathrm{mM}$ acetic acid containing $5 \%$ ethylene glycol, $\mathrm{pH}$ 3.7. The mixture was reextracted for $5 \mathrm{~min}$ in a vortex mixer, followed by centrifugation. Fluorescence of the remaining aqueous phase containing the drug was measured with a Karl-Zeiss PMQ III fluorimeter using the following excitation/emission wavelengths: $\lambda$ excitation: 290 $\mathrm{nm}$ and $\lambda$ emission: $358 \mathrm{~nm}$.

Data analysis

Plasma propranolol concentration versus time data were plotted for comparison of the two routes of administration. The data obtained were maximum plasma concentration $\left(\mathrm{C}_{\mathrm{MAX}}\right)$ and time to reach it $\left(\mathrm{T}_{\mathrm{MAX}}\right)$. Noncompartmental pharmacokinetics was applied to estimate pharmacokinetic parameters $(10$, 11). The area under the curve integrated from zero to $120 \mathrm{~min}\left(\mathrm{AUC}_{\mathrm{T}}\right)$ was calculated by the linear trapezoidal rule. Extension of bioavailability of propranolol (EBA) was calculated based on the area under curve ratio, AUCsublingual/AUCperoral x 100 .
Estimated parameters related to drug absorption as $\mathrm{AUC}_{\mathrm{T}}, \mathrm{EBA}$ and drug elimination as total body clearance $\left(\mathrm{CL}_{\mathrm{T}} / \mathrm{F}\right)$ : dose/ $\mathrm{AUC}_{\mathrm{T}}$ (where $\mathrm{F}$ represents the bioavailability of drug) were calculated according to Ritschel (10) and Shargel (11).

Pharmacodynamic parameters such as systolic blood pressure (SBP), DBP and HR were measured to evaluate drug effect. The antihypertensive effect was plotted against time or against plasma propranolol concentration.

Ethics

The study was submitted to the Heart Institute Ethics Committee, University of São Paulo (São Paulo, Brazil) and approved without any restriction. All patients gave informed written consent to participate in the investigation.

Statistical analysis

Results and estimated parameters are reported as mean $\pm \mathrm{SD}$. The chi-square test was applied to determine the frequency distribution of all variables and parametric data analysis was performed for the pharmacokinetic and pharmacodynamic statistics. The Student t-test for unpaired data was applied for statistical analysis of propranolol kinetic disposition. Two-way analysis of variance for repeated measures was also applied to the pharmacodynamic data. The level of $\mathrm{P}<0.05$ was considered to be statistically significant.

\section{Results}

The clinical baseline features of the patients are listed in Table 1.

\section{Pharmacokinetics}

Plasma concentration data versus time were plotted for comparison of propranolol 
Table 2 - Pharmacokinetic parameters after propranolol administration to ambulatory patients with severe essential arterial hypertension.

Data are reported as the mean $\pm \mathrm{SD} .{ }^{*} \mathrm{P}<0.05$ compared to peroral administration. $\mathrm{C}_{\text {MAX: }}$ Peak plasma concentration; $T_{M A X}$ : time to reach $\mathrm{C}_{\mathrm{MAX}}$ EBA: extension of bioavailability (sublingual versus peroral); $A \cup C_{T}$ : area under the plasma concentration-time curve; $\mathrm{CL}_{T} / \mathrm{F}$ : total body clearance.

\begin{tabular}{lrc}
\hline & Sublingual & Peroral \\
\hline$C_{M A X}(\mathrm{ng} / \mathrm{ml})$ & $147 \pm 72^{*}$ & $41 \pm 12$ \\
$T_{M A X}(\mathrm{~min})$ & $34 \pm 18^{*}$ & $52 \pm 11$ \\
$\mathrm{AUC}_{\mathrm{T}}\left(\mathrm{ng} \mathrm{h} \mathrm{h} \mathrm{ml}^{-1}\right)$ & $245 \pm 134^{*}$ & $79 \pm 54$ \\
$\mathrm{CL}_{T} / \mathrm{F}\left(\mathrm{ml} \mathrm{min}^{-1} \mathrm{~kg}^{-1}\right)$ & $44 \pm 23$ & $26 \pm 12$ \\
$\mathrm{EBA}(\%)$ & $314 \pm 53$ & -
\end{tabular}

administration by the two routes. The data obtained were $\mathrm{C}_{\operatorname{MAX}}$ and $\mathrm{T}_{\mathrm{MAX}}$. Noncompartmental pharmacokinetics was applied to estimate pharmacokinetic parameters such as $\mathrm{AUC}_{\mathrm{T}}, \mathrm{EBA}$ and $\mathrm{CL}_{\mathrm{T}} / \mathrm{F}$ (Table 2). The pharmacokinetic parameters obtained or estimated after sublingual or peroral drug administration were, respectively: $\mathrm{C}_{\mathrm{MAX}}: 147 \pm$ 72 vs $41 \pm 12 \mathrm{ng} / \mathrm{ml}, \mathrm{P}<0.05 ; \mathrm{T}_{\mathrm{MAX}}: 34 \pm 18$ vs $52 \pm 11 \mathrm{~min}, \mathrm{P}<0.05 ; \mathrm{AUC}_{\mathrm{T}}: 245 \pm 134$ vs $79 \pm 54 \mathrm{ng} \mathrm{h}^{-1} \mathrm{ml}^{-1}, \mathrm{P}<0.05 ; \mathrm{CL}_{\mathrm{T}} / \mathrm{F}: 44 \pm 23 \mathrm{vs}$ $26 \pm 12 \mathrm{ml} \mathrm{min}^{-1} \mathrm{~kg}^{-1}, \mathrm{P}=\mathrm{NS}$ (Table 2).

Pharmacodynamics

Pharmacodynamic parameters for patients from both groups investigated are reported in Table 3. Patients receiving sublingual propranolol showed a drop (baseline vs maximum dose effect at $120 \mathrm{~min}$ ) of $17 \%$ in SBP, from $210 \pm 30$ to $175 \pm 31 \mathrm{mmHg}(\mathrm{P}=0.05)$, a $14 \%$ reduction in DBP, $132 \pm 16$ to $114 \pm$ $10 \mathrm{mmHg}(\mathrm{P}<0.05)$, and a $22 \%$ reduction in $\mathrm{HR}, 81 \pm 8$ to $63 \pm 8 \mathrm{bpm}(\mathrm{P}<0.01)$. Patients receiving peroral propranolol showed: SBP reduced from $208 \pm 18$ to $170 \pm 12 \mathrm{mmHg}$ (equivalent to $18 \%, \mathrm{P}<0.01$ ) while a slight but significant reduction from $125 \pm 5$ to 115 $\pm 9 \mathrm{mmHg}$ (equivalent to $8 \%, \mathrm{P}<0.05$ ) was obtained for DBP; HR was reduced from 87 \pm 12 to $63 \pm 6 \mathrm{bpm}$ (equivalent to $28 \%$, $\mathrm{P}<0.01$ ). Significant reductions of BP and HR were obtained at 120 min compared to baseline after propranolol administration by both routes, while no differences in these parameters were observed when the sublingual and peroral routes were compared as follows: SBP (17 vs $18 \%, \mathrm{P}=\mathrm{NS})$, DBP (14 vs $8 \%, \mathrm{P}=\mathrm{NS})$ and $\mathrm{HR}(28$ vs $22 \%, \mathrm{P}=\mathrm{NS})$, respectively.

Adverse effects

All patients complained of mouth paresthesia, from mild (3/7) to moderate (4/7), after sublingual propranolol while no adverse effects were observed in patients after peroral administration.

\section{Discussion}

Pharmacokinetics

Faster drug absorption may occur in the oral cavity after sublingual administration when compared to drug absorption in the gastrointestinal tract after peroral administration $(12,13)$. However, propranolol hydrochloride tablets are fully absorbed in the gastrointestinal tract after administration by the peroral route and only $10-30 \%$ of the administered dose was available in the systemic circulation as active drug. Considering this extensive first-pass hepatic effect on the drug administered by the peroral route, metabolic deactivation of propranolol can be significantly reduced by administration by the sublingual route and consequently higher drug plasma concentrations are expected.

Because of high hepatic extraction, propranolol is a drug with a short half-life when compared to other water-soluble beta adrenoceptor antagonists. On the other hand, propranolol has a lipidophilic structure, the major factor causing a reduction of systemic availability when the drug is administered by the 
peroral route. Additionally, it is a basic drug tightly bound to plasma proteins and widely distributed in all body compartments. Its kinetic disposition reported previously also shows a proportion of $3: 1$ for the plasmasaliva ratio after a single $80-\mathrm{mg}$ peroral dose (14). Considering also drug availability reported previously, it was demonstrated that extension of bioavailability was increased approximately two-fold by food, suggesting a reduction of propranolol metabolism in nonfasting patients (15). In the present study, the systemic availability measured by the $\mathrm{AUC}_{\mathrm{T}}$ ratio indicated that the three-fold increase in extension of bioavailability was probably a consequence of the reduction of the first-pass effect plus faster drug absorption $\left(\mathrm{C}_{\mathrm{MAX}}\right.$ increased by 3 times and a shortening of $\mathrm{T}_{\mathrm{MAX}}$ ) when propranolol was administered by the sublingual rather than the peroral route. Finally, significant changes in pharmacokinetics were obtained when this unusual route was used for patients with essential arterial hypertension, and could be an alternative choice for propranolol administration when faster drug absorption is desired.

Pharmacodynamics

The control of noninvasively determined parameters such as blood pressure and heart rate is critical to reverse pathogenic conditions responsible for morbidity and mortality related to hypertensive crises (16). Decreases in blood pressure and heart rate may also be important to prevent cardiovascular events in several groups of patients (17), particularly in those with ischemic heart disease $(18,19)$. The therapeutic range for plasma propranolol concentrations remains unknown due to a large interindividual variation and to associated diseases (20-23). Reduction of blood pressure and heart rate correlates with plasma propranolol levels (24). Plasma propranolol levels higher than $20 \mathrm{ng} / \mathrm{ml}$, defined as minimum effective con-
Table 3 - Hemodynamic parameters obtained before and after oral and sublingual propranolol administration.

Data are reported as the mean $\pm S D$. SL, Sublingual route; SBP, systolic blood pressure; DBP, diastolic blood pressure; HR, heart rate. ${ }^{*} t$-test (baseline vs $120 \mathrm{~min}$ ).

\begin{tabular}{|c|c|c|c|c|c|c|}
\hline \multirow{2}{*}{$\begin{array}{l}\text { Time } \\
\text { (min) }\end{array}$} & \multicolumn{2}{|c|}{$\mathrm{SBP}(\mathrm{mmHg})$} & \multicolumn{2}{|c|}{$\mathrm{DBP}(\mathrm{mmHg})$} & \multicolumn{2}{|c|}{$\mathrm{HR}(\mathrm{bpm})$} \\
\hline & SL & Oral & SL & Oral & SL & Oral \\
\hline 0 & $210 \pm 30$ & $208 \pm 18$ & $132 \pm 16$ & $125 \pm 5$ & $81 \pm 8$ & $87 \pm 12$ \\
\hline 10 & $202 \pm 35$ & $194 \pm 14$ & $130 \pm 18$ & $119 \pm 9$ & $77 \pm 10$ & $78 \pm 6$ \\
\hline 20 & $195 \pm 30$ & $190 \pm 14$ & $128 \pm 17$ & $117 \pm 17$ & $72 \pm 8$ & $73 \pm 5$ \\
\hline 30 & $188 \pm 30$ & $185 \pm 13$ & $125 \pm 13$ & $125 \pm 8$ & $68 \pm 9$ & $68 \pm 7$ \\
\hline 60 & $179 \pm 23$ & $176 \pm 11$ & $123 \pm 11$ & $116 \pm 10$ & $65 \pm 7$ & $72 \pm 12$ \\
\hline 120 & $175 \pm 31$ & $170 \pm 12$ & $114 \pm 10$ & $115 \pm 9$ & $63 \pm 8$ & $63 \pm 6$ \\
\hline $\begin{array}{l}\% \text { Reduction } \\
\text { at } 120 \mathrm{~min}\end{array}$ & $17 \%$ & $18 \%$ & $14 \%$ & $8 \%$ & $22 \%$ & $28 \%$ \\
\hline${ }^{*} P$ & 0.05 & $<0.0001$ & 0.02 & 0.02 & 0.001 & $<0.0001$ \\
\hline
\end{tabular}

centration, were sufficient to obtain a clinical response by beta-adrenoceptor blockage, but better results for the antihypertensive effect can be achieved at plasma levels ranging from 50 to $100 \mathrm{ng} / \mathrm{ml}(12,25,26)$. In the present study, comparison of a single dose of sublingual and peroral propranolol showed similar clinical efficacy despite the higher plasma levels achieved after sublingual administration as a consequence of increased systemic availability, and the drug effect, measured by blood pressure and heart rate, was not proportional. This was probably related to the small number of patients, but similar results were previously obtained after intravenous and peroral propranolol administration (27). In our previous study with more patients we showed the clinical efficacy of sublingual propranolol administration and also counteracted the tachycardia reflex associated with sublingual nifedipine (8). We also might consider the high interindividual variability of the clinical response involving several mechanisms and enantioselectivity of drug action, and finally, the consequences on the kinetic disposition of this drug of high extraction, extensive first- 
pass route-dependent effect and active metabolites (21-23,28-32). Nevertheless, one could speculate that, when high blood levels of propranolol are desired, this unusual route of administration might be an efficient and safe alternative to the intravenous or peroral route of propranolol administration.

\section{References}

1. Conolly ME, Kersting $F$ \& Dollery $C T$ (1976). The clinical pharmacology of betaadrenoceptor blocking drugs. Progress of Cardiovascular Diseases, 19: 203-234.

2. Frishman WH (1981). ß-Adrenoceptor antagonists: new drugs and new indications. New England Journal of Medicine, 305: 500-506.

3. Watanabe AG (1983). Recent advances in knowledge about beta-adrenergic receptors: Application to clinical cardiology. Journal of the American College of Cardiology, 1: 82-89.

4. Wood AJJ, Carr K, Vestal RE, Belcher S, Wilkinson GR \& Shand DG (1978). Direct measurement of propranolol bioavailability during accumulation to steady state. British Journal of Clinical Pharmacology, 6: 345-350.

5. Chidsey CA, Marselli P, Bianchetti G, Morganti A, Leonetti $G$ \& Zanchetti $A$ (1975). Studies of the absorption and removal of propranolol in hypertensive patients during therapy. Circulation, 52: 313318.

6. Cid E, Mella F, Lucchini L, Carcamo M \& Monasterio J (1986). Plasma concentrations and bioavailability of propranolol by oral, rectal and intravenous administration in man. Biopharmaceutics and Drug Disposition, 7: 559-566.

7. Landau AJ, Frishman WH, Alturk N, AdjeiPoku $M$, Fornasier-Bongo $M$ \& Furia $S$ (1993). Improvement in exercise tolerance and immediate beta-adrenergic blockage with intranasal propranolol in patients with angina pectoris. American Journal of Cardiology, 72: 995-998.

8. Mansur AP, Ramires JAF, Avakian SD, Paula RS \& Pileggi $F$ (1991). Efeito comparativo do diazepam, nifedipina, propranolol e da associação nifedipina e propranolol, por via sublingual, em pacientes com crise hipertensiva. Arquivos Brasileiros de Cardiologia, 57: 313-317.

9. Rao PS, Quesada LC \& Mueller HS (1978). A simple micromethod for simultaneous determination of plasma propranolol and 4-hydroxy-propranolol. Clinica Chimica Acta, 88: 355-361.

10. Ritschel WA (1986). Handbook of Basic Pharmacokinetics. 3rd edn. Drug Intelli- gence Publications, Bethesda.

11. Shargel $L \& Y u A B C$ (1993). Applied Biopharmaceutics and Pharmacokinetics. 3rd edn. Prentice-Hall International Inc., New York.

12. Johnsson G \& Regardh C-G (1976). Clinical pharmacokinetics of beta-adrenoceptor blocking drugs. Clinical Pharmacokinetics, 1: 233-263.

13. Beckett $A H$ \& Triggs EJ (1967). Buccal absorption of basic drugs and its application as an in vivo model of passive drug transfer through lipid membranes. Journal of Pharmacy and Pharmacology, 19 (Suppl S): S-31-S-41.

14. Mahajan P, Grech ED, Pearson RM, Ridgway EJ \& Turner P (1984). Propranolol concentrations in blood serum, seminal plasma and saliva in man after a single oral dose. British Journal of Clinical Pharmacology, 18: 849-852.

15. Melander A, Danielson K, Schersten B \& Wahlin E (1977). Enhancement of the bioavailability of propranolol and metoprolol by food. Clinical Pharmacology and Therapeutics, 22: 108-112.

16. Calhoun DA \& Oparil S (1990). Treatment of hypertensive crisis. New England Journal of Medicine, 323: 1177-1183.

17. The 1988 Report of the Joint National Committee on Detection, Evaluation, and Treatment of High Blood Pressure (1988). Archives of Internal Medicine, 148: 10231038.

18. Braunwald E, Muller JE, Kloner RA \& Maroko PR (1983). Role of beta-adrenergic blockage in the therapy of patients with myocardial infarction. American Journal of Medicine, 74: 113-123.

19. Frishman WH (1983). Multifactorial actions of beta-adrenergic blocking drugs in ischemic heart disease: current concepts. Circulation, 67 (Suppl I): I-11-I-18.

20. Holford NHG \& Sheiner LB (1981). Understanding the dose-effect relationship: clinical application of pharmacokineticpharmacodynamic models. Clinical Pharmacokinetics, 6: 429-453.

21. Frishman $W H$, Furberg $C D$ \& Friedewald WT (1984). ß-Adrenergic blockage for survivors of acute myocardial infarction. New England Journal of Medicine, 310: 830837.
22. McDevitt DG (1979). Adrenoceptor blocking drugs: Clinical pharmacology and therapeutic use. Drugs, 17: 267-288.

23. Walle T, Webb JG, Bagwell EE, Walle UK, Daniell HB \& Gaffney TE (1988). Stereoselective delivery and actions of beta receptor antagonists. Biochemical Pharmacology, 37: 115-124.

24. Coltart DJ, Gibson DG \& Shand DG (1971) Plasma propranolol levels associated with suppression of ventricular ectopic beats. British Medical Journal, 1: 490-491.

25. Frishman WH (1982). The beta-adrenoceptor blocking drugs. International Journal of Cardiology, 2: 165-178.

26. Coltart DJ \& Shand DG (1970). Propranolol levels in the quantitative assessment of ß-adrenergic blockage in man. British Medical Journal, 3: 731-734.

27. Frohlich ED, Tarazi RC, Dustan HP \& Page IH (1968). The paradox of beta-adrenergic blockage in hypertension. Circulation, 37: 417-423.

28. Shand DG, Nuckolls EM \& Oates JA (1970). Plasma propranolol levels in adults with observation in four children. Clinical Pharmacology and Therapeutics, 11: 112120.

29. Lennard MS, Jackson PR, Freestone $S$, Tucker GT, Ramsay LE \& Woods HF (1984). The relationship between debrisoquine oxidation phenotype and the pharmacokinetics and pharmacodynamics of propranolol. British Journal of Clinical Pharmacology, 17: 679-685.

30. Bowman SL, Hudson SA, Simpson G, Munro JF \& Clements JA (1986). A comparison of the pharmacokinetics of propranolol in obese and normal volunteers. British Journal of Clinical Pharmacology, 21: 529-532.

31. Poirier JM, LeJeunne C, Cheymol G, Cohen A, Barre J \& Hughes FC (1990). Comparison of propranolol and sotalol pharmacokinetics in obese subjects. Journal of Pharmacy and Pharmacology, 42: 344-348.

32. Cheymol G, Poirier J-M, Barre J, Pradalier A \& Dry J (1987). Comparative pharmacokinetics of intravenous propranolol in obese and normal volunteers. Journal of Clinical Pharmacology, 27: 874-879. 